\title{
Extracranial Carotid Atherosclerosis and Acute Ischemic Stroke in a Tertiary Hospital in Burkina Faso
}

\author{
Alfred Anselme Dabilgou ${ }^{*}$, Alassane Dravé ${ }^{2}, J^{\prime}$ ulie Marie Adeline Kyelem ${ }^{1}$, Hassan Koanda ${ }^{1}$, \\ Christian Napon ${ }^{3}$, Jean Kaboré ${ }^{1}$
}

${ }^{1}$ Department of Neurology, University Hospital Yalgado Ouedraogo, Ouagadougou, Burkina Faso

${ }^{2}$ Department of Neurology, Regional University Hospital of Ouahigouya, Ouahigouya, Burkina Faso

${ }^{3}$ Department of Neurology, University Hospital of Bogodogo, Ouagadougou, Burkina Faso

Email: *dabilgouanselm@yahoo.fr

How to cite this paper: Dabilgou, A.A., Dravé, A., Kyelem, J.M.A., Koanda, H., Napon, C. and Kaboré, J. (2019) Extracranial Carotid Atherosclerosis Andacute Ischemic Stroke in a Tertiary Hospital in Burkina Faso. World Journal of Neuroscience, 9, 39-51.

https://doi.org/10.4236/wjns.2019.92003

Received: February 5, 2019

Accepted: May 6, 2019

Published: May 9, 2019

Copyright $\odot 2019$ by author(s) and Scientific Research Publishing Inc. This work is licensed under the Creative Commons Attribution International License (CC BY 4.0).

http://creativecommons.org/licenses/by/4.0/

\begin{abstract}
Objective: To determine the prevalence and risk factors of carotid atherosclerosis among ischemic stroke patients in a tertiary hospital in Burkina Faso. Methodology: This was a descriptive and analytical retrospective study of patients admitted at neurology department of Yalgado Ouedraogo University Teaching Hospital with ischemic stroke and cerebral large vessel atherosclerosis in the period from January 1, 2012 to December 31, 2016. Results: The prevalence of extracranial carotid atherosclerosis was $23.9 \%$. The mean age of patients was 63.5 years (Range 31 - 90 years). The study population included $65 \%$ of men and $35 \%$ of women. Hypertension was the most common vascular risk factor (75.6\%). Stroke was mostly located in the anterior circulation in $23.9 \%$. Low HDL-C was present in $52 \%$ of patients. The majority of plaque was homogeneous $(85.2 \%)$. Plaque were located in carotid bulbar artery (38.5\%) followed by common carotid artery (28.2\%) and extracranial internal carotid artery (18.6\%). According to cerebral lesion, plaque was bilateral in $45.5 \%$, ipsilateral in $42.3 \%$ and contralateral in $12.1 \%$ of cases. Tight stenosis was found in $30.1 \%$ of patients. There was a significant link between male gender and tight stenosis $(\mathrm{p}=0.004)$. Aspirin was the most antiplatelet therapy used $(95.5 \%)$. Statin therapy was used in $91 \%$ of patients. The mean duration of hospitalization was 12.5 days with a mortality rate of $7.1 \%$. Conclusions: Our study showed that extra carotid atherosclerosis was the most common cause of ischemic stroke in Burkina Faso. Man gender was most represented than women.
\end{abstract}

\section{Keywords}

Ischemic Stroke, Extracranial Atherosclerosis, Antiplatelet Therapy, Burkina Faso 


\section{Introduction}

Stroke is the second most common cause of death worldwide [1]. The incidence of stroke, a cardinal complication of cardiovascular risk factors, appears to be rising in Africa and other low- and middle-income country (LMIC) settings [2]. Therefore, $86 \%$ of all stroke deaths around the world were contributed by LMIC in Africa and other continents [3]. Atherosclerotic disease is one of the major causes of ischemic stroke. Cerebral atherosclerosis can be divided into extracranial atherosclerosis (ECAS) and intracranial atherosclerosis (ICAS). Carotid artery disease appears to be uncommon in stroke patients in Sub Saharan Africa [4]. In previous studies, carotid atherosclerosis had been associated with stroke among Africans [5] [6] [7]. Patients with a first ischemic stroke are at high risk of developing recurrent stroke due to carotid atherosclerotic plaque rupture [8]. Recurrent ischemic stroke in patients with carotid plaque was significantly aggravated compared with those in patients who have experienced one stroke [9]. Extracranial carotid artery disease was estimated to be responsible for $20 \%-30 \%$ of ischemic strokes in the United States and Western communities [10]. Therefore, the presence of an atherosclerotic lesion in the carotid bulb or in the extracranial internal carotid artery (ICA) is associated with elevated stroke risk [8]. Race-ethnic differences in the distribution of atherosclerosis are well described. Whites tend to have a higher prevalence of extracranial carotid atherosclerosis than African Americans [11]. In Sub Saharan Africa, especially in Burkina Faso, the prevalence of extracranial carotid atherosclerosis is unknown. The aim of this study was to determine the frequency and risk factors of extracranial carotid atherosclerosis in acute ischemic stroke patients by using Doppler ultrasound, a noninvasive and cost-effective investigation, recommended for the initial evaluation of symptomatic and asymptomatic patients with suspicion for carotid atherosclerotic disease [12].

\section{Methodology}

\subsection{Study Design}

This study was conducted in the neurology department of the Yalgado Ouedraogo University Teaching hospital located in Ouagadougou (Burkina Faso). Burkina Faso is a French speaking country in West Africa who covers an area of $274,000 \mathrm{~km}^{2}$ with a population estimated at 16.248 .558 inhabitants according to 2006 Census. The overall mortality rate is $11.8 \%$ and the life expectancy at birth is 56.7 years [13].

\subsection{Study Population}

We conducted a 4 years retrospective study on acute ischemic stroke patients admitted at neurology department of Yalgado Ouedraogo University hospital in Ouagadougou (Burkina Faso) during the period from January 2012 to December 2016. We included patients aged over 18 years old who had carotid atherosclero- 
sis on Doppler Ultrasound. All the patients had done carotid Doppler ultrasound and further CT angiography if possible. We excluded posterior circulation ischemic stroke, stroke with cardio aortic embolic cause, lacunar stroke, vasculitis, arterial dissection, or fibro muscular dysplasia were excluded on the study.

\subsection{Data and Analysis}

The data were collected and analyzed using the EPI Info software version 7. The results were expressed as a percentage and/or on average. The Pearson Chi-square statistical test was used for the comparison of proportions. $\mathrm{P}$ values less than 0.05 were considered statistically significant. The following variables were taken into account in our study: Sociodemographic data and risk factors (age, sex, residence, occupation, modifiable risk factors, i.e. hypertension, dyslipidemia, smoking, obesity, diabetes, alcohol consumption) alcohol, oral contraception, pregnancy, migraine and sickle cell disease). Clinical data (The reason for admission, motor deficit, sensory disorders, cognitive functions (oral and written language, praxis, gnosis, memory) and the methods of management (drugs and physiotherapy)). Data from brain imaging (vascular territory, number of lesions, laterality of lesions), as well as associated signs (cerebral atrophy, cerebral ede$\mathrm{ma}$ ), cervical ultrasound, data from biological assessments (total cholesterol, HDL cholesterol, LDL cholesterol, triglycerides, blood glucose, serum creatinine, and electrocardiogram).

\subsection{Ethical and Ethical Considerations}

For this study, we asked for the agreement of the head of neurology department of Yalgado Ouedraogo University Teaching Hospital. Written informed consent from the patients was not required in this retrospective review. All patient records and information were anonymized and deidentified before analysis.

\subsection{Definitions}

Ischemic stroke was defined according to the sudden appearance of neurological symptoms lasting more than $24 \mathrm{~h}$, in the absence of hemorrhagic signs on the first brain CT scan. The diagnosis of extracranial atherosclerosis was defined by the presence of cholesterol plaque or stenosis in an extracranial artery. We used the criteria of the Nascet [14] to define the degree of carotid stenosis. Hypertension was defined as a self-reported history, taking antihypertensive medication, or a systolic blood pressure $\geq 140 \mathrm{~mm} \cdot \mathrm{Hg}$, or a diastolic blood pressure of $\geq 90$ $\mathrm{mm} \mathrm{Hg}$ at baseline. Diabetes mellitus was defined as a self-reported history, current treatment with insulin or oral hypoglycemic agents, or fasting blood glucose level $\geq 7.0 \mathrm{mmol} / \mathrm{l}$ at baseline. Dyslipidemia was defined as a self-reported history, current use of cholesterol lowering medicine, or a total cholesterol level $\geq$ $6.22 \mathrm{mmol} / \mathrm{l}$ or triglyceride $\geq 2.26 \mathrm{mmol} / \mathrm{l}$ or low density lipoprotein $\geq 4.14$ $\mathrm{mmol} / \mathrm{l}$ at baseline. Table 1 shows the normal value of lipids. 
Table 1. Value of normal value of lipid.

\begin{tabular}{ccc}
\hline Lipoproteins & Normal $(\mathrm{mmol} / \mathrm{l})$ & High $(\mathrm{mmol} / \mathrm{l})$. \\
\hline Total cholesterol & $<6.20$ & $\geq 6.20$ \\
HDL cholesterol & $>1$ & $\geq 1.54$ \\
LDL cholesterol & $<4.12$ & $\geq 4.12-4.87$ \\
Triglycerid & $<1.71$ & $\geq 1.71$ \\
\hline
\end{tabular}

\section{Results}

\subsection{Frequency of Extracranial Carotid Atherosclerosis}

During study period, 653 patients with ischemic stroke were admitted in Neurology Department. Of whom, 156 (23.9\%) had anterior circulation stroke and extracranial carotid atherosclerosis on carotid Ultrasound Doppler.

\subsection{Sociodemographic and Clinical Characteristics of Population Study}

From 156 patients included in the study, 83 (53.2\%) were male and 73 (46.8\%) female with the mean age of 63.5 years $+/-11.7$ (Ranging from 31 to 90 years). Among male patients, the mean age was 64 years while in females it was 63 years. About $63.4 \%$ of patients were above 60 years of age $(n=99)$. One hundred thirty five (86.5\%) subjects were married and $21(13.5 \%)$ were single. Seventy six (48.7\%) patients had educated. The residence was living in urban in 88 (56.4\%) patients. According to profession, 63 (40.4\%) patients were housewives, 28 (18\%) retired and 27 (17.3\%) famers. According to education level, 77 (49.4\%) patients were illiterate. The medical records of the subjects studied showed that 23 (14.7\%) patients had no identifiable risk factors for atherosclerosis whilst 7 (23.3\%) subjects had at least one risk factor for atherosclerosis. Among the later, hypertension was found in 118 (75.6\%) patients, hyperglycemia in 71 (32.7\%) patients, chronic alcohol consumption in 54 (34.6\%) and cigarette smoking in 28 (18.2\%). Nineteen (12.2\%) patients had past history of ischemic stroke. The Sociodemographic and clinical characteristics of the participants are summarized in Table 2.

\subsection{Lipid Profile}

According to lipid profile, high level of TC was present in 69 (44.3\%) patients, LDL C in 58 (37.2\%) patients and TG in 42 (27\%). Eight (5.2\%) patients had high level of HDL C.

\subsection{Characteristics of Ischemic Stroke Lesions}

The majority of ischemic stroke lesions was located in Middle carotid artery in 138 (88.4\%) patients. Eighty (51.2\%) patients had right sided stroke, 73 (46.7\%) left sided stroke and 3 (1.9\%) bilateral involvement. Table 3 presents the location of stroke in the 156 patients with extracranial carotid atherosclerosis. 
Table 2. Sociodemographic and clinical characteristics of the participants.

\begin{tabular}{|c|c|}
\hline Sociodemographic and clinical characteristics & Population study $(\mathrm{N}=156)$ \\
\hline \multicolumn{2}{|l|}{ Age group (years) } \\
\hline$<30$ & 0 \\
\hline $31-40$ & $8(5.1 \%)$ \\
\hline $41-50$ & $14(8.9 \%)$ \\
\hline $51-60$ & $35(22.4 \%)$ \\
\hline $61-70$ & $57(36.5 \%)$ \\
\hline $71-80$ & $34(21.7 \%)$ \\
\hline$\geq 80$ & $8(5.1 \%)$ \\
\hline Male & $83(53.2 \%)$ \\
\hline Married & $128(82.05)$ \\
\hline Illiterate & $77(49.4 \%)$ \\
\hline Primary level & $32(20.5)$ \\
\hline Secondary level & $42(26.9 \%)$ \\
\hline University level & $5(3.2 \%)$ \\
\hline Urban residence & $88(56.4 \%)$ \\
\hline \multicolumn{2}{|l|}{ Vascular risk factors } \\
\hline Hypertension & $118(75.6 \%)$ \\
\hline Hyperglycemia & $71(32.7 \%)$ \\
\hline Chronic alcohol consumption & $54(34.6 \%)$ \\
\hline Cigarette smoking & $29(18.5 \%)$ \\
\hline Obesity & $27(17.3 \%)$ \\
\hline Diabetes mellitus & $24(15.3 \%)$ \\
\hline Previous Stroke & $19(12.1 \%)$ \\
\hline Sickle cell disease & $4(2.5 \%)$ \\
\hline Contraception & $2(1.2 \%)$ \\
\hline
\end{tabular}

Table 3. Location of stroke in the 156 patients with extracranial carotid atherosclerosis.

\begin{tabular}{ccccc}
\hline \multicolumn{5}{c}{ Location } \\
\hline Cerebral artery & Number $(\mathrm{n}=156)$ & Right side $(\mathrm{n}=80)$ & Left side $(\mathrm{n}=73)$ & Bilateral $(\mathrm{n}=3)$ \\
\hline$M C A$ & $138(88.4 \%)$ & 67 & 68 & 3 \\
$A C A$ & $12(7.6 \%)$ & 10 & 2 & 0 \\
$\mathrm{MCA}+\mathrm{ACA}$ & $6(3.8 \%)$ & 3 & 6 & 0 \\
\hline
\end{tabular}

MCA: middle cerebral artery; ACA: anterior cerebral artery.

\subsection{Neuroimaging of Extracranial Atherosclerosis}

Doppler ultrasound was performed in the totality of patents. Atherosclerotic le- 
sions were mostly located in carotid bulbar artery in 60 (38.5\%). The lesions were unilateral in $86(55.2 \%)$ patients and bilateral in $70(44.8 \%)$ patients. According to cerebral lesion, plaque was ipsilateral in $66(42.3 \%)$ patients, contralateral in $19(12.1 \%)$ and bilateral in $71(45.5 \%)$ patients. The site of plaque was unilateral in $86(55.2 \%)$ patients and bilateral in $70(44.8 \%)$ patients. Right side plaque was seen in $53(33.1 \%)$ and left side plaque in $33(21.1 \%)$ patients. Plaque was calcified in $7(4.4 \%)$ patients, soft in 148 (94.8\%) patients and mobile in a male patient $(0.6 \%)$ patient. The nature of plaque was homogenous in 133 $(85.2 \%)$ and heterogeneous in $33(10.2 \%)$. According to degree of stenosis, 30 (19.2\%) patients had mild stenosis, 79 (50.6\%) had moderate stenosis and 47 (30.2\%) had tight stenosis. Among patients with tight stenosis ( $\mathrm{n}=47)$, occlusion was found in $3(6.3 \%)$, all located in carotid bulbar. Table 4 summarizes Ultrasound characteristics of extracranial carotid atherosclerosis $(\mathrm{N}=156)$. CT angiography was performed in 5 (3.2\%) patient's further carotid Doppler ultrasound and confirmed the presence of atherosclerosis plaque in the totality of cases. Calcifications were present in $3(60 \%)$ patients and tight stenosis in 4 (80\%) patients.

\subsection{Risk Factors for Tight Stenosis}

According to gender, tight stenosis was more present in male patient than in female patients $(\mathrm{p}=0.004)$. Table 5 gives the degree of stenosis according to patient's gender. According to age, tight stenosis was more present in male patients after the age of 45 years $(\mathrm{p}=0.0001)$ and in female patients after the age of 55 years $(\mathrm{p}=0.013)$. Table 6 gives the distribution of tight stenosis in male and female patients according to age $(\mathrm{N}=156)$. The prevalence of tight stenosis was respectively $75 \%$ in sickle cell disease, $70.8 \%$ in diabetes mellitus $(70.8 \%)$ and $64.8 \%$ in cigarette smoking $(64.8 \%)$. Table 7 presents the frequency of tight stenosis according to vascular risk factors $(\mathrm{N}=156)$. The prevalence of tight stenosis was respectively $50.7 \%$ in patients with high level of TC, $73.8 \%$ in patients with high triglyceride and $43.1 \%$ in patients with LDL cholesterol. The prevalence of tight stenosis in patients with high level of HDL C was $100 \%$. Table 8 describes the distribution of lipid profile of patients with tight stenosis.

Table 4. Ultrasound characteristics of extracranial carotid atherosclerosis $(\mathrm{N}=156)$.

\begin{tabular}{ccc}
\hline Characteristic & Number $(\mathrm{N}=156)$ & Percentage (\%) \\
\hline Plaque & 133 & 85.25 \\
Overload & 103 & 66.02 \\
Calcification & 48 & 30.76 \\
Severe stenosis & 47 & 30.12 \\
Occlusion & 4 & 2.56 \\
Wall thrombosis & 3 & 1.92 \\
\hline
\end{tabular}


Table 5. Degree of carotid stenosis according to patients' gender $(\mathrm{N}=156)$.

\begin{tabular}{ccccc}
\hline $\begin{array}{c}\text { Degree of } \\
\text { carotid stenosis }\end{array}$ & $\begin{array}{c}\text { Population study } \\
(\mathbf{N}=150)\end{array}$ & Male (n= 83) & Female (n= 73) & P value \\
\hline$<60$ & $30(19.2 \%)$ & $13(43.3 \%)$ & $17(56.6 \%)$ & \\
$60-70$ & $79(50.6 \%)$ & $41(51.8 \%)$ & $38(48.1 \%)$ & \\
$\geq 70$ & $47(30.2 \%)$ & $29(5.0 \%)$ & $18(38.2 \%)$ & 0.004 \\
\hline
\end{tabular}

Table 6. Distribution of tight stenosis in male and female patients according to age $(\mathrm{N}=$ 156).

\begin{tabular}{ccccc}
\hline Age and gender & Number $(\mathrm{n}=156)$ & Carotid stenosis $\geq 70 \%$ & OR (IC 95\%) & p-value \\
\hline Male gender & 83 & $\mathbf{2 9}(\mathbf{3 4 . 9})$ & & \\
$<45$ years & 6 & 16.6 & & \\
$\geq 45$ years & 77 & 36.3 & $1.5(0.5-4.3)$ & $\mathbf{0 . 0 0 1}$ \\
Female gender & 73 & $\mathbf{1 8}(\mathbf{2 4 . 6})$ & & \\
$<55$ years & 15 & 22.4 & & \\
$\geq 55$ years & 58 & 33.3 & $1.2(0.1-3.5)$ & $\mathbf{0 . 0 1 3}$ \\
\hline
\end{tabular}

Table 7. Frequency of tight stenosis according to vascular risk factors $(\mathrm{N}=156)$.

\begin{tabular}{cc}
\hline Vascular risk factors & Stenosis ${ }^{>} 70 \%$ \\
\hline Hypertension $(\mathrm{n}=118)$ & $47(39.8 \%)$ \\
Hyperglycemia $(\mathrm{n}=71)$ & $35(49.2 \%)$ \\
Chronic alcohol consumption $(\mathrm{n}=54)$ & $35(64.8 \%)$ \\
Cigarette smoking $(\mathrm{n}=29)$ & $21(72.4 \%)$ \\
Obesity $(\mathrm{n}=27)$ & $18(66.6 \%)$ \\
Diabetes mellitus $(\mathrm{n}=24)$ & $17(70.8 \%)$ \\
Previous Stroke $(\mathrm{n}=19)$ & $12(63.1 \%)$ \\
Sickle cell disease $(\mathrm{n}=4)$ & $3(75 \%)$ \\
\hline
\end{tabular}

Table 8. Distribution of lipid profile of patients with tight stenosis.

\begin{tabular}{ccc}
\hline Lipid profile & Population study $(\mathbf{n}=156)$ & Stenosis $>70 \%)$ \\
\hline Total cholesterol & $87(55.7 \%)$ & $12(13.7 \%)$ \\
Normal & $69(44.3 \%)$ & $35(50.7 \%)$ \\
High & & \\
Triglycerid & $114(73 \%)$ & $16(14.03 \%)$ \\
Normal & $42(27 \%)$ & $31(73.8 \%)$ \\
High & & $22(22.4 \%)$ \\
LDL cholesterol & $98(62.8 \%)$ & $25(43.1 \%)$ \\
Normal & $58(37.2 \%)$ & $8(100 \%)$ \\
High & & $39(26.3 \%)$ \\
HDL cholesterol & $8(5.2 \%)$ & \\
High & $148(94.8 \%)$ & \\
Normal & &
\end{tabular}




\subsection{Treatments of Atherosclerosis Stroke}

According to treatment, aspirin was used in 149 (95.5\%) patients. Dual antiplatelet therapy (DAPT) with aspirin and clopidogrel was prescribed in $6(3.8 \%)$ patients. Statin therapy was used in $142(91 \%)$ patients. The mean duration of hospitalization was 12.5 days (range 2 - 53 days). The hospital stays was 5 - 10 days in $69(44.2 \%)$ patients, $>10$ days in $54(34.6 \%)$ patients and $<5$ days in $33(21.2 \%)$. Eleven (7.1\%) patients died during hospitalization course. One hundred and five (86.5\%) patients were discharge to rehabilitation.

\section{Discussion}

\subsection{Frequency of Extracranial Carotid Atherosclerosis}

Our study had shown that the frequency of ECCA was $23.9 \%$, in concordance with literature. About $30 \%-60 \%$ of ischemic strokes are caused by atherosclerotic disease in the USA and Western communities [10] [15]. In developing countries, the prevalence of extracranial atherosclerosis, using carotid Doppler, ranges from $27.4 \%$ in Iran to $78 \%$ in India [16] [17] [18]. According to autopsies studies, the prevalence of ECCA varied from $73.3 \%$ to $94 \%$ [19] [20]. The difference between these studies is due metrological features (location of study, size of study population).

\subsection{Characteristics of Population Study}

The majority of patients with atherosclerosis in this study was male (53.2\%), in concordance with many studies [17] [18] [21] [22] [23]. The explanation is that hormonal factors such as estrogen have been observed to play a significant role in slowing the progression of atherosclerotic lesions in females. Also, there was significant relation between male gender and severe atherosclerosis $(p=0.005)$. According to literature, male gender is also risk factor for extracranial atherosclerosis in Asia [24] [25]. The mean age of patients was $63.5+/-11.7$ years, comparable to that found by Hadi [17] (62.43 years) but the proportion of patients above 60 years was higher than his study:63.4\% versus 55\%.In our study, male patients above 45 years and female patients above 55 years had more risk to have severe stenosis than other patients. Older age is an important risk factor for extracranial carotid atherosclerosis, especially in the Chinese and South Koreans [24] [26] [27].

Hypertension was the most vascular risk factor (75.6\%) in patients with extracranial carotid atherosclerosis followed by chronic alcohol consumption (34.6\%) and cigarette smoking (18.2\%). Hypertension was also found to be the major risk factor of extracranial carotid atherosclerosis in other studies [17] [21] [28] [29] [30]. Smoking is also known to be associated with atherosclerosis of the extracranial carotid vessels [27]. The frequency of DM in our study was less frequent in diabetic patients in our study (15.3\%) than in the study of Hadi (44\%) [17]. $\mathrm{DM}$ is an important risk factor for extracranial carotid atherosclerosis [25] [27]. While tight stenosis was most frequent in SCD (75\%) and chronic alcohol con- 
sumption $(64.8 \%)$, none study had established a possible role of these vascular risk factors and carotid atherosclerosis. The high frequency of theses is due to its association with hypertension, diabetes mellitus and smoking. In our study, 85\% of patients had at least more than 2 vascular risk factors. According to SCD, it is a genetic disease, frequently present in stroke patients in Burkina Faso [31]. Hyperlipidemia was present in $32.7 \%$ of patients with carotid atherosclerosis. Tula Dhār in Nepal had showed that almost all of patients of ischemic stroke had both hyperlipidemia and extracranial atherosclerosis on Doppler ultrasound [32]. Also, hyperlipidemia was found to be a common risk factor for extracranial atherosclerosis in Asia [24]. According to lipid profile, high level of TC was observed in $44.3 \%$, LDL C in $37.2 \%$, TG in $27 \%$. The progression of CA atherosclerosis was associated with a higher level of TG, LDL-C, or a lower level of HDL-C [33]. We had observed a highest prevalence of tight stenosis in patients with high level of HDL had tight stenosis (100\%). This situation was controverly according to literature which reported that HDL C cholesterol appeared to be particularly protective against the atherosclerotic stroke subtype [34]. There was a poor frequency of patients who had initially high level of HDL C (5.2\%).

\subsection{Carotid Ultrasound}

About $30.2 \%$ of patients with extracranial carotid atherosclerosis had tight stenosis with higher frequency than that found by Hadi (8.9\%) [17], Razzaq et al. (21\%) [28] and Wasay et al. (12\%) [35]. Occlusion of the internal carotid artery was found in $6.3 \%$ of cases, in concordance with a previous study (2.5\%) [36]. In contrast, high incidence of occlusive extracranial internal carotid artery lesions (up to 57\%) was found in patients with large hemispheric infarctions [37]. In a post mortem studies, the prevalence of steno occlusive carotid lesion was $64 \%$ of the patients studied [38]. Plaque calcifications were found in $4.4 \%$ of patients. The risk of embolization or rapid progression would depend on plaque composition especially if it was heterogeneous, diffuse, or focal [39]. In our study, ICA was found to be the commonest site affected as found by other studies. Majority of patients in our study had soft plaques (94.8\%) which is in accordance with a study conducted by Razzaq et al. (43\%) [28] and Hadi (58.9\%) [17]. Mobile plaque in internal carotid was present in a male patient in concordance with Bhatti who found that the thrombus is mostly frequent in the internal carotid artery (75\%) [40]. This is a very rare ultrasonographic finding which is usually diagnosed after a neurological emergency, such as a transient ischemic attack or cerebral infarction [41]. The etiology of mobile thrombus can be cardioembolism, arterio-arterial embolism, dissection, complicated atherosclerotic plaque and hypercoagulable states [42].

\subsection{Treatments}

Antiplatelet therapy (DAPT) and statin therapy were the main treatments in ischemic stroke due to atherosclerosis, as in our study but in sometimes, aspirin was prescribed together with low molecular weight heparin [43]. According to 
literature, statins may also act on biological markers of plaque instability and reduced the carotid intima media thickness consistently with all statins. [44] [45]. In our study, about $30 \%$ of patients had straight stenosis but none had carotid endaterectomy which is the most common surgical procedure used to treat stenosis of the extracranial precerebral carotid artery. The reason is the lack of materials and only two vascular surgeons for all the country of 20 million of population.

\subsection{Limitations of the Study}

The present study has some limitations. As this study was a single hospital-based study conducted on patients belonging to lower socioeconomic status having a different clinical and risk factor profile, these results cannot be applied to the general population. According to Ultrasound Doppler, some data (velocity, IMT, number of plaque etc.) were missing in the conclusion of operators. Carotid Doppler was made by many operators (radiologists and cardiologists) in our context, so the result differed from operator.

\section{Conclusion}

Our study had shown that extracranial carotid stenosis was frequent in ischemic stroke patients in Burkina Faso, especially in older patients and men. To reduce the risks of carotid atherosclerosis among these patients, we need to do systematic carotid ultrasound in all patients with vascular risk factors (hypertension, smoking and hyperlipidemia). Also, we need to increase the financial access to cerebral angiography and training for neurosurgeon to do carotid endarterectomy.

\section{Acknowledgements}

We wish to thank Ms. David Koura, M.Sc. for valuable comments on a former version of this paper.

\section{Conflicts of Interest}

With regard to the present study none of the authors has to disclose conflicts of interest.

\section{References}

[1] Beaglehole, R. and Yach, D. (2003) Globalisation and the Prevention and Control of Non-Communicable Disease: The Neglected Chronic Diseases of Adults. The Lancet, 362, 903-908. https://doi.org/10.1016/S0140-6736(03)14335-8

[2] Moran, A., Forouzanfar, M., Sampson, U., et al. (2013) The Epidemiology of Cardiovascular Diseases in Sub-Saharan Africa: The Global Burden of Diseases, Injuries and Risk Factors 2010 Study. Progress in Cardiovascular Diseases, 56, 234-239. https://doi.org/10.1016/j.pcad.2013.09.019

[3] Feigin, V.L. (2005) Stroke Epidemiology in the Developing World. The Lancet, 365, 2160-2161. https://doi.org/10.1016/S0140-6736(05)66755-4 
[4] Jusabani, A., Gray, W.K., Swai, M., et al. (2011) Post-Stroke Carotid Ultrasound Findings from an Incident Tanzanian Population. Neuroepidemiology, 37, 245-248. https://doi.org/10.1159/000334610

[5] Agunloye, A.M. and Owolabi, M.O. (2014) Exploring Carotid Sonographic Parameters Associated with Stroke Risk among Hypertensive Stroke Patients Compared to Hypertensive Controls. Journal of Ultrasound in Medicine, 33, 975-983. https://doi.org/10.7863/ultra.33.6.975

[6] Owolabi, M.O. and Agunloye, A.M. (2013) Risk Factors for Stroke among Patients with Hypertension: A Case-Control Study. Journal of the Neurological Sciences, 325, 51-56. https://doi.org/10.1016/j.jns.2012.11.016

[7] Owolabi, M.O., Agunloye, A.M. and Ogunniyi, A. (2014) The Relationship of Flow Velocities to Vessel Diameters Differs between Extracranial Carotid and Vertebral Arteries of Stroke Patients. Journal of Clinical Ultrasound, 42, 16-23. https://doi.org/10.1002/jcu.22053

[8] Spagnoli, L.G., Mauriello, A., Sangiorgi, G., et al. (2004) Extracranial Thrombotically Active Carotid Plaque as a Risk Factor for Ischemic Stroke. JAMA, 292, 1845-1852. https://doi.org/10.1001/jama.292.15.1845

[9] Liu, X.S., Zhao, H.L., Cao, Y., et al. (2012) Comparison of Carotid Atherosclerotic Plaque Characteristics by High-Resolution Black-Blood MR Imaging between Patients with First-Time and Recurrent Acute Ischemic Stroke. American Journal of Neuroradiology, 33, 1257-1261. https://doi.org/10.3174/ajnr.A2965

[10] Grau, A.G., Weimar, C., Buggle, F., et al. (2001) Risk Factors, Outcome, and Treatment in Subtypes of Ischemic Stroke. The German Stroke Data Bank. Stroke, 32, 2559-2566. https://doi.org/10.1161/hs1101.098524

[11] Rundek, T., Arif, H., Boden-Albala, B., et al. (2008) Carotid Plaque, a Subclinical Precursor of Vascular Events: The Northern Manhattan Study. Neurology, 70, 1200-1207. https://doi.org/10.1212/01.wnl.0000303969.63165.34

[12] Brott, T.G., Halperin, J.L., Abbara, S., et al. (2011) Guideline on the Management of Patients with Extracranial Carotid and Vertebral Artery Disease. Circulation, 124, e54-e130.

[13] Ministry of Health of Burkina Faso. (2011) Statistical Yearbook.

[14] Nascet, C. (1991) Beneficial Effect of Carotid Endarterectomy in Symptomatic Patients with High-Grade Carotid Stenosis. North American Symptomatic Carotid Endarterectomy Trial Collaborators. The New England Journal of Medicine, 325, 445-453. https://doi.org/10.1056/NEJM199108153250701

[15] Timsit, S.G., Sacco, R.L., Mohr, J.P., et al. (1992) Early Clinical Differentiation of Cerebral Infarction from Severe Atherosclerotic Stenosis and Cardioembolism. Stroke, 23, 486-491. https://doi.org/10.1161/01.STR.23.4.486

[16] Mousavi, S.A., Ghasemi, M., Hoseini, T., et al. (2006) Extra-Cranial Cerebral Arterial Artherosclerosis in Iranian Patients Suffering Ischemic Stokes. Journal of Research in Medical Sciences, 11, 388-390.

[17] Ulhadi, N., Khan, R., Awan, K.H., et al. (2009) Frequency of Carotid Artery Stenosis in Ischemic Stroke by Using Carotid Doppler Ultrasonography in a Teaching Hospital. Gomal Journal of Medical Sciences, 7, 82-85.

[18] Fernandes, M., Keerthiraj, B. and Mahale, A.R. (2016) Evaluation of Carotid Arteris in Stroke Patients Using Color Doppler Sonography: A Prospective Study Conducted in a Tertiary Care Hospital in South-India. International Journal of Applied and Basic Medical Research, 6, 38-44. https://doi.org/10.4103/2229-516X.174007

[19] Erete, E.I., Ogun, O.G., Oladapo, O.O., et al. (2012) Prevalence and Severity of 
Atherosclerosis in Extra Cranial Carotid Arteries in Nigeria: An Autopsy Study. BMC Cardiovascular Disorders, 12, 106. https://doi.org/10.1186/1471-2261-12-106

[20] Dalager, S., Paaske, W.P., Kristensen, I.B., et al. (2007) Artery-Related Differences in Atherosclerosis Expression Implication for Atherogenesis and Dynamics in Intima-Media Thickness. Stroke, 38, 2698-2705. https://doi.org/10.1161/STROKEAHA.107.486480

[21] Atif, M.A., Ali, H. and Mahmood, T. (2008) Frequency of Carotid Artheroscerosis in Cerebral Infraction. Pakistan Journal of Medical Sciences, 24, 69-73.

[22] Masoud, S.A. (2002) A Survey on the Prevalence of Stroke Risk Factors in CVA Diagnosed Patients, Hospitalized in Shahid, Beheshti Hospital in 1998. Iranian Journal of Public Health, 31, 21-22.

[23] Khan, S.N. and Vohra, E.A. (2007) Risks Factors for Strokes: A Hospital Base Study. Pakistan Journal of Medical Sciences, 23, 17-22.

[24] Kim, J.S., Nah, H.W., Park, S.M., et al. (2012) Risk Factors and Stroke Mechanisms in Atherosclerotic Stroke: Intracranial Compared with Extracranial and Anterior Compared with Posterior Circulation Disease. Stroke, 43, 3313-3318.

https://doi.org/10.1161/STROKEAHA.112.658500

[25] Pan, X.F., Lai, Y.X., Gu, J.Q., et al. (2016) Factors Significantly Associated with the Increased Prevalence of Carotid Atherosclerosis in a Northeast Chinese Middle-Aged and Elderly Population: A Cross-Sectional Study. Medicine (Baltimore), 95, e3253. https://doi.org/10.1097/MD.0000000000003253

[26] Kim, Y.D., Choi, H.Y., Jung, Y.H., et al. (2009) Classic Risk Factors for Atherosclerosis Are Not Major Determinants for Location of Extracranial or Intracranial Cerebral Atherosclerosis. Neuroepidemiology, 32, 201-207.

https://doi.org/10.1159/000195690

[27] Liu, C.Y. and Chen, C.Q. (2014) Intra- and Extracranial Atherosclerotic Stenosis in China: Epidemiology, Diagnosis, Treatment and Risk Factors. European Review for Medical and Pharmacological Sciences, 18, 3368-3379.

[28] Razzac, A., Khan, B. and Jadoon, C. (1999) Carotid Doppler Ultrasonography in Young Stroke Patients. Journal of Pakistan Medical Association, 49, 97-99.

[29] Safeer, M., Tariq, M. and Rehman, U. (2008) Frequency of Risk Factors of Cerebral Infarction in Stroke Patients. A Study of 100 Cases in Naseer Teaching Hospital, Peshawar. Pakistan Journal of Medical Sciences, 24, 109-113.

[30] Ahmad, A., Usman, F. and Hassan, A. (2008) Risk Factors and Pattern of Stroke in Islamabad. Rawal Medical Journal, 34, 47-50.

[31] Napon, C., Kaboré, A., Ouédraogo, M., et al. (2012) Strokes and Hemoglobinopathies in Burkina Faso. Medecine et Sante Tropicales, 22, 390-393.

[32] Tuladhar, A.S., Shrestha, A., Adhikari, P., et al. (2012) Carotid Doppler and Lipid Profile Findings in Ischemic Stroke Patients-A Hospital Based Study. Nepal Medical College Journal, 15, 98-101.

[33] Vouillarmet, J., Helfre, M., Maucort-Boulch, D., et al. (2016) Carotid Atherosclerosis Progression and Cerebrovascular Events in Patients with Diabetes. Journal of Diabetes and its Complications, 30, 638-643. https://doi.org/10.1016/j.jdiacomp.2016.01.022

[34] Grira, M., Damak, M., Ammou, B.S. and Mhiri, C. (2008) Recommendation on the Management of Acute Stroke. Maghrébine de Neurosciences, 60, 1845-1861.

[35] Wasay, M., Azeemuddin, M., Masroor, I., et al. (2009) Frequency and Outcome of Carotid Atheromatous Disease in Patients with Stroke in Pakistan. Stroke, 40, 
708-712. https://doi.org/10.1161/STROKEAHA.108.532960

[36] Chang, Y.J., Lin, S.K., Ryu, S.J. and Wai, Y.Y. (1995) Common Carotid Artery Occlusion: Evaluation with Duplex Sonography. American Journal of Neuroradiology, 16, 1099-1105.

[37] Lim, S.N., Chang, Y.J. and Lin, S.K. (2016) Extracranial Carotid Artery Disease; Risk Factors and Outcomes in Patients with Acute Critical Hemispheric Ischemic Stroke. Journal of Ultrasound in Medicine, 35, 341-348. https://doi.org/10.7863/ultra.15.03070

[38] Schulte-Altedorneburg, G., Droste, D.W., Felszeghy, S., et al. (2002) Detection of Carotid Artery Stenosis by in Vivo Duplex Ultrasound: Correlation with Planimetric Measurements of the Corresponding Postmortem Specimens. Stroke, 33, 2402-2407. https://doi.org/10.1161/01.STR.0000030111.34093.02

[39] Tegos, T.J., Sabetai, M.M., Nicolaides, A.N., et al. (2000) Comparability of the Ultrasonic Tissue Characteristics of Carotid Plaques. Journal of Ultrasound in Medicine, 19, 399-407. https://doi.org/10.7863/jum.2000.19.6.399

[40] Bhatti, A.F., Leon Jr., L.R., Labropoulos, N., et al. (2007) Free-Floating Thrombus of the Carotid Artery: Literature Review and Case Reports. Journal of Vascular Surgery, 45, 199-205. https://doi.org/10.1016/j.jvs.2006.09.057

[41] Bajko, Z., Balasa, R., Petrutiu, S., et al. (2009) Mobile Carotid Artery Thrombus. Roman J Neurol., 8, 184-186.

[42] Chua, H.C., Lim, T., Teo, B.C., et al. (2012) Free-Floating Thrombus of the Carotid Artery Detected on Carotid Ultrasound in Patients with Cerebral Infarcts: A 10-Year Study. Annals Academy of Medicine Singapore, 41, 420-424.

[43] Bajko, Z., Maier, S. and Russu, S. (2015) Acute Ischaemic Stroke Secondary to a Mobile Thrombus in the Common Carotid Artery-Case Report. The Journal of Critical Care Medicine, 1, 68-70. https://doi.org/10.1515/jccm-2015-0010

[44] Crisby, M., Nordin-Fredriksson, G., Shah, P.K., et al. (2001) Pravastatin Treatment Increases Collagen Content and Decreases Lipid Content, Inflammation, Metalloproteinases, and Cell Death in Human Carotid Plaques: Implications for Plaque Stabilization. Circulation, 103, 926-933. https://doi.org/10.1161/01.CIR.103.7.926

[45] Takemoto, M. and Liao, J.K. (2001) Pleiotropic Effects of 3-Hydroxy-3-Methylglutaryl Coenzyme a Reductase Inhibitors. Arteriosclerosis, Thrombosis, and Vascular Biology, 21, 1712-1719. https://doi.org/10.1161/hq1101.098486

\author{
Abbreviations \\ TC: Total Cholesterol \\ HDL C: High Density Lipoprotein Cholesterol \\ LDL C: Low Density Lipoprotein Cholesterol \\ TG: Triglycerides \\ SCD: Sickle Cell Disease
}

